\title{
Western and Traditional Educational Background of Midwives and Delivery Pain Control among Women in Cross River State, Nigeria
}

\author{
Oyira, Emilia James ${ }^{1}$, Emon, Umoe Duke ${ }^{1}$, Essien, N. C. ${ }^{1}$, Ekpenyong, Affiong Onoyom ${ }^{2}$ \\ ${ }^{1}$ RN, RM, B.Sc, PGDNFS, M.Sc,NFS, Ph.DNFS, FWACN, Department of Nursing Science University of Calabar, \\ Calabar-Nigeria \\ ${ }^{2}$ Department of Public Health, College of Health Technology, Calabar, Nigeria \\ Correspondence: Oyira, Emilia James, RN, RM, B. N. Sc, RPN, PGDE, M.ED, MSN, Ph. D, FWACN, Department of \\ Nursing Science, University of Calabar, Calabar-Nigeria
}

\author{
Received: January 9, 2015 Accepted: January 23, 2015 Online Published: March 18, 2015 \\ doi:10.11114/jets.v3i3.728 URL: http://dx.doi.org/10.11114/jets.v3i3.728
}

\begin{abstract}
This study sought to investigate western and traditional educational background of midwives with regard to their effectiveness in delivery pain control in Cross River State - Nigeria. To achieve this purpose, two null hypotheses were formulated to guide the investigation. The study adopted the survey design. The sample consisted of 360 post-natal women selected from a population of 78,814 through the polio immunization registers of selected health centers. Accidental sampling technique was used to select the respondents. The instrument used for collecting data for the study was a 36-item questionnaire. Independent t-test and contingency chi-square were used in testing the null hypotheses. The result showed that women delivered by traditional midwives have more positive control of delivery pain caused by attitude of midwives than their counterparts who delivered by the western midwives; On the basis of these finding it was concluded that western midwives are actually different from their counterparts. All what they need is workshops, seminar, conferences during ante-natal period to acquaint the traditional midwives with delivery related activities and procedures. It was also recommended that the traditional midwives should be given adequate western training retain so that they can face the society and avoid further complications. Government should also continue to train more midwives to avoid negative attitudes towards their clients.
\end{abstract}

Keywords: educational background of midwives, delivery pain control, postnatal women

\section{Introduction}

\subsection{Background to the Study}

In all societies today, the birth of a baby is a momentous occasion. The details of the experiences surrounding the whole event are etched on one's memory forever. Delivery pain is a global phenomenon experienced by every woman going through child delivery. This places huge responsibility on midwives in helping women through child delivery and are recognized worldwide in that capacity. In this sense, the western midwife plays a key role in promoting the antenatal and post-natal health of childbearing women and their families (Cooper, 2003).

Traditional midwives do the same but they cannot be considered as skillful health services providers as their counterparts trained in a formal institutions. Though they hold special positions in many communities and are considered part of the communities' informal health care system; they have no formal training on how to carry out their operations, they indulge in crude methods of health care delivery. As a result many women suffer complications under them. They brandish operational paraphernalia in the hospital environment, thereby scaring the clients, and more often, their bills too expensive, unnecessary protocols, job stress, and huge number of patients. The direct consequence is that nurses no longer meet up with the demands of patients owing to lack of interest and care on the patients, and this leads to patronage of the traditional midwives, (Rajan, 1993 and Pang, et al 2002).

According to (Kitzinger, 1987), pain delivery control is the way individuals or groups of midwives manage their clients in pain. Whipple (1984) states that, the way an individual perceives and reacts to delivery pain is affected by many different factors. Fear, anxiety, depression, personality distortion, fatigue, age and senility, socio-cultural factor and previous experiences, etc add up. Delivery pain is a peculiar experience that can only be well explained by women who 
had passed through child-birth experience.

Experiences have shown that many women prefer going to traditional midwives than the hospital. Reasons are ascribed to time wasting, payment of bills, and lengthy "unnecessary" protocols. Apart from this, some women andrelatives feel that some western midwives have very unfriendly attitude which can cause spontaneous abortion. Besides, when the client is due for delivery she must have to produce all necessary papers to prove that she has been consulting in that health center for the past six months. Even when this is done, there is always a deposit required to be paid before anything is done. Kitzinger (2000) states that,in Nigeria traditional midwives help mothers to wash napkins hospital midwives do not have such time. All of these make traditional midwives to win the confidence of women both in urban and rural areas. The understanding of the rural women in particular about the hospital is that it is a place for educated and wealthy people, (Ihejiamaizu, 2002). Furthermore, it is a place where surgical operations are carried out hence they hate it. Any mention of going to hospital no matter how critical their condition may be, radiate fear and anxiety. This may result to serious shock even death for fear of surgery and administration of injections. This scares them and open ways for traditional midwives. In some communities, traditional midwives are full-time health workers who can be called upon by anyone and who expect to be paid either in cash or in kind. A number of studies (Maternal and Neonatal Health (MNH 2000) have generated international interest in traditional healthcare providers, and several countries like UK, Asia and Europe among others have started training traditional midwives in clean and safe home delivery. For more than 20 years, bilateral and international donor agencies, non-governmental organization (NGOs), and local organizations have invested their resources in traditional midwives training programme, with the expectation that traditional midwives would help reduce maternal mortality rate in Nigeria.

Maternal and Neonatal Health (MNH 2000) studies of the effectiveness of these training programmes, however, showed that reductions in maternal mortality occurred only in areas where the traditional midwives had skills backup support. The studies found that the majority of the programmes were ineffective because traditional midwives did not have sufficient literacy or general knowledge of delivery pain when they started their training. Without supervision and backup support, they tended to slide back into old ways and were not able to prevent death when life-threatening complications arose during childbirth. These complications arose because traditional midwives are not only ill-equipped for the job; they lack knowledge of the full delivery process.

\subsection{Purpose of the Study}

The purpose of this study was to determine if midwives trained under the western educational background differs from the traditional educational background with regards to their effectiveness in delivery pain control among women in Cross River State, Nigeria.

(i) Specifically, the study investigates the difference between women who delivered through the western midwives and those who delivered through traditional educational system in their control of clients care giving.

(ii) The study also examines the difference between women who delivered through western trained midwives and those of traditional educational system in their control of attitude towards delivery pains.

\subsection{Research Questions}

(i) What is the difference in care giving of those trained under western education than those traditional midwives informally trained midwives?

(ii) What is the difference in the attitude of midwives trained under western education from those informally trained traditional midwives?

\subsection{Research Hypothesis}

$\mathbf{H}_{\mathbf{0 1}}$

Those trained under western education do not differ significantly from traditional midwives in their control of delivery pain caused by amount of care giving.

Independent variable: Type of midwife

Dependent variable: control of delivery pain caused by amount of care giving.

Test statistic used: independent t-test analysis

$\mathbf{H}_{\mathbf{0 1}}$

Those trained under western education do not differ significantly from traditional midwives in their control of delivery pain caused by attitude of midwives. 
Independent variable: Type of midwife

Dependent variable: Control of delivery pain as caused by attitude of midwife.

Test statistic used: independent t-test analysis.

\section{Review of Related Literature}

\subsection{Control of Women towards Delivery Pain Caused By Amount of Care Giving by Both}

\subsubsection{Western and Traditional Midwives}

Since trained midwives have expertise in the care of normal pregnancy and birth, they are in a good position to provide general care and support to the woman when there is need.To enable them make physical and social adjustments usually associated with pregnancy and delivery. In addition to clinical skills, trained midwives provide information and advices and in many cases, social support. Their standard of care is quite different with that of traditional midwives (Crafter, 1997). Midwifery care is relatively short term and arrangements for care do not always facilitate continuity of career, but interventions during certain critical periods that may have a long term impact, however small as (Crafter, 1997) noted when breast feeding babies. When woman needs advices and social support than those provided through the maternity services, midwives play key roles in providing relevant information and advice in referring them to other professionals and organizations for support (Crafter, 1997).

Recently, a United Kingdom (UK) Government, in conjunction with Nigeria Government prepared policy framework to recognize the difficulties caused in practice by the institutional split among health, social and community services. The nursing and midwifery advisory committee (for England and Wales, with similar reports for Nigeria) in 1998 advised a stronger public health role for the midwife through changing the organization of care and expanding or reviewing the scope of the midwife's roles and responsibilities (DOH 1998). Although it does not set out the precise nature of this expanded role or how it would be achieved, it recommended more integrated models of care, with midwives working across hospitals and community service boundaries, including, with personal or group practice caseloads. The report also advocates a stronger public health role in collaboration with other primary care practitioners with all women on health promotion and in services to provide additional support to socially disadvantaged women, (DOH and SUMAC, 1998). The health promotion role advocated for trained midwives is particularly through health education for women and through focusing care on women with particular needs for support arising from problems such as domestic violence, substance abuse, and diseases which can negatively affect the long term health of mothers and children. This emphasis on health promotion is reflected in the policy document making the difference (DOH, 1999). The report proposes that maternity services increase integrated care system and health promotion work with midwives working across traditional boundaries, collaborating with other primary care practitioners and taking on expanded roles to support women's health during delivery. DOH (1999), states that although much of the midwife's work is primary and preventive health care, there have been little involvement of the midwife in the new focus on primary health services. Trained midwives under western education clearly should have important role in public health as now advocated by the government policy.

In Nigeria, traditional health care had been practiced long before the arrival of foreign explorers, traders, missionaries, and colonial administrators. Since it is difficult to delineate precisely the data between traditional medicine and scientific health care in any country (WHO, 1992). Suffice it then to say that traditional health in Nigeria is as old as the earliest known communities in Nigeria. Traditional healers are known in their communities as competent to provide health care by using herb, animal and mineral substance including divination, experience methods based on social, cultural and religious background, knowledge, attitude and beliefs that are prevalent in the community regarding physical, mental and social well-being and the causation of disease and disability (Bannerman, 1982). Furthermore, Yusuf (1990) observed that traditional medicine as the term use to indicate "ancient and cultic-bound care practices that existed before the application of science to health matters" (Lucas and Gilles, 2003).

Traditional midwives specialize in the use of concoctions derived from leave, roots, animals, and folk remedies, Bannerman (1982) posited that traditional midwives give advice on child case, infertility, use of contraceptives, abortions, performs rituals and religious rites such as enchantments and female genital mutilations, (Maternal \& Neonatal Health, 2007). The work of traditional midwives is diverse. In many societies, traditional birth attendants do much more than they suggest (MNH, 2007). Prenatally, they visits expectant mothers in the early part of pregnancy to enable her determine expected date of delivery. MNH (2007) noted that traditional midwives perform the first massage on the visit client's first visit. They believe that it helps in softening the uterus in readiness for labour. They advise clients on diet in pregnancy and sexual relationship with husband. On follow up visits, they assess the progress of pregnancy and make free use of herbal treatment for abnormal symptoms including pain relievers, discomfort and position of the foetus (Lucas and Gilles, 2003). 
From the background of the researchers, it was observed that traditional midwives sometimes use occultic means in predicting the sex of the baby. Their disadvantages during the pre-natal period include unregulated regime for intended care since most of them are not educated and have little or no formal training in the anatomy and physiology of pregnancy of the human body. They find it difficult to calculate the estimated date of delivery; hence they use the appearance of the moon to approximate the months. So they find it difficult to diagnose preterm and prolonged pregnancy (post-maturity). Herbs are given liberally to expectant mothers without giving consideration to the side effect(s), because they do not have a good standard of care and measure. In most cases the herbs are toxic to the foetus and result to intra-uterine death (IUD) according to DOH (1999) of the foetus. They lack the knowledge of how to use equipment in assessing the well being of the foetus like foetal stethoscope, sonic aid or sonny machine which makes it difficult to detect and this result to baby distress or intrauterine death (IUD).

Abnormal presentations are viewed as bad omen and thus rituals are carried out to appease the gods as a standard of care to the client. This has to be done before a traditional birth attendant will touch the woman to deliver the head of the baby. In the $3^{\text {rd }}$ stage of labour placenta separation is not observed. The placenta is delivered with the use of dirty instruments. Care is not given to the contraction of the uterus and as such, act of negligence may result to severe bleeding and even the death of the woman (MNH, 2007). Postnatal, the work of traditional midwives may continue after delivery. Traditional midwives give assistance to mother and child, by performing activities of house cleaning, washing and cooking. This gives the mother enough time to rest and be with her baby, (Walsh 2000).

In Asia, Middle East, and Central America, midwives administer sits bath and roots to return the uterus to its pre-gravid state and prevent soreness (MNH, 2007). In the Philippines, women who have just put to birth lie over fire for one to two hours several times a day. This practice is based on the believe that if the body becomes cold after delivery, a woman may develop complications such as uterine backache. Traditional birth attendants understand, sympathetic, and very interested in their job. They attend to women in labour at their homes or the women's homes. This may take place in the bathroom or bedroom without consideration to hygienic standards. There is no designated room for deliveries (JRSPH, 2007).

Traditional midwives are not trained in any formal institution which carries out deliveries itself and are therefore, inexperienced and carry out unsafe practices (Central Bureau of Health in Cell Gene, Health sector policy options, 2007). Traditional birth attendants are hardly supplied with kits which include hygienic dressing and basic equipment kit containing items of basic requirement. Plastic containers to enhance cleaning, gloves, blades, scissors, kidney tray, soap, forceps, cord clamp, nail brush, sterile dressing and pad, shaving kit, disinfectant, scales for newborn weighing. Their education, training and skills of traditional midwives and birth attendants cannot qualify them sufficiently to fulfill all the requirements for management of normal pregnancies, births identification and management for referral in case of complications. Their strong cultural and traditional belief may influence their practices and thereby impede the effectiveness of their training to be of standard in the traditional medicine (Lucas and Gilles, 2003). A variety of factors affect the intensity and amount of pain experienced by women in labour. These include:

1. Control of pain

2. Culture, movement and positioning

3. The birth plan

4. Women's control of pain during labour

5. Pain control and sometosensory sensation

6. The physiology of pain

7. Pain transmission

The biological, psychological, social, spiritual, and educational dimensions of each woman have an impact on how she expresses herself, and indeed, how she perceives pain during labour. The challenge for midwifery is to provide adequate and adapted care for each child bearing woman. The essence of midwifery is to be "with woman", providing comfort in labour. Historically, the maintenance of health has been the role of women in health care delivery system (Kitzinger, 2000). Women have, throughout the ages, supported and helped each other during the process of birth. There is much literature to venerate the presence of TBAs, midwife or friend of the birthing woman descent a soothing positive effect on the outcome of labourer or talent. A lot of midwifery and medical research has indicated that the one to one support by a midwife during labour reduces the need for analgesia and improves the birth experience of the mother during delivery (Halldorsdottir and Karlsdottir, 1996). Some evidence still suggests that midwives continue to emphasize pharmacological methods and techniques to control pain in labour rather than assisting women to use their own personal ability to cope with delivery pain (Niven,and Brodie 1995).

Odent (1984) has always defended a philosophy of natural child birth, constantly believing in the aptitude and innate capability of the birthing woman. The midwife is a key figure in this process, supporting and assisting women through child birth. Other reports reveal that there is little conformity between how women themselves perceive their pain relief 
and how this is viewed by the medical personnel. Medical staff believes that pain relief is sufficient for the woman whereas women themselves feel that it is not (Rajan, 1993). Mander (1992) states that the pain itself and its severity, plus the side effects of medication make it difficult for women to maintain control during labour. Women then require care, support, attention and advice at this time. Concerns have been raised as to whether women in labour, or the technology that seems to be so conspicuous at this time, is the centre of attention and consideration of professionals (Deakin, 2001; Gould, 2000; Walsh, 2000). Although advance in technology and devices available assist in birth process, the woman and her family must remain at the centre of attention of the midwife. Halldorsdottir and Karlsdottir (1996) states that a midwife who is involved in the woman's life experience of giving birth is one who improves this experience for her.

There is a lot to be said on approach where the woman dictates the course of events and adapts to the activity of the uterus. This could well be considered to be an example of women-centred care. It was also, remarked in some quarters how women move and swing their pelvis, thereby accommodating the passage of the fetal head through it (Kizinger, 2000). Walsh (2000) stated that the compelling logic of gratuity, meaning birthing in an upright position should make us wonder how it has become routine practice to deliver in a semi recumbent position.

Walsh (2000) recommends that mobility in labour should be encouraged as it lessens the need for pharmacological analgesia. It has been argued that midwives should adapt their role, attitude and care to each child bearing woman (Deakin 2001). Hallodorsdottir and Karlsdottir (1996) Lundgren and Dhalberg (1998), and Walsh (2000) remarked that there is enough evidence to suggest that women are still being subjected to invasive procedures that invariably increase, not lessen, pain in labour and thereby failing to improve women's experience of child birth. Pain control during labour is a woman-centred concept. There is so much evidence to suggest that women are not always more satisfied by a birth experience that is pain free (Fairlie et al, 1999). Midwives are therefore required to give control of the pain to women rather than eradicating it (Mander, 1992). The same author states that a clear differentiation must be made between the traditional goal of pain relief and the control of pain in labour. There is no evidence to suggest that information is of lesser importance to women of lower socio-economic status. Midwives must take into account that high expectations that antenatal do not impact negatively on women's experience of birth (Green, Coupland, and Kitzinger, 1998).This evidence should be used by midwives to provide women-centred care, and Walsh states "knowledge is power but a positive anticipation of birth is consistent with viewing it as a physiological event" (Walsh, 2000).

The role of the midwife then is to encourage and assist women to anticipate positively the birth of their baby. Two studies carried out in Japan revealed the intensity of memorized labour pain (Kabegama and Myoshi, 2001).That self control is the most important predictor of satisfactory child birth experience for mothers. They stated that, women who viewed labour as a challenge, in their attempt to control their breathing and relaxation, had much better outcomes. These active attitudes are supposed to reflect the positive attitudes to everything in daily life by the individual. The studies goes on to say that not only does the removal of excessive fear and anxiety make a birth experience more satisfactory but that, it also increases the mother's pride and self-confidence.Pain sensation may therefore be distinguished from other sensations, although emotions such as fear and anxiety are also experienced at the same time, thereby affecting the person's control of pain. It must be remembered that a painful stimulus may induce such changes by the sympathetic nervous system as increased heart rate, a rise in blood pressure, release of adrenaline (epinephrine) into the bloodstream and an increase in blood glucose levels. There is a decrease in gastric motility and a reduction in the blood supply to the skin, causing sweating. Thus, stimulus that causes pain results in a sensory incident or occurrence (Rajan 1993). In case of acute pain, sensations are transmitted along delta fibers, which are large diameter nerve fibers. This type of pain is perceived as being a pricking pain that is readily localized by the sufferer (Bevis, 1984).

\subsection{Control of Women towards Delivery Pain Caused by Attitude of both Western and Traditional Midwives}

In every aspect of life, people need friendliness, care and proper attitude and approach to issues that concern them. Once this is done, the clients have no problem in falling like a prey to the professionals in question. Traditional midwives are no exception to this irrefutable fact. pregnant women are treated with dispatch devoid of protocol. They are not pedantic but consider the safety of the clients first before anything. This is not the case in hospitals with Western midwives (Walsh, 2000). Secondly, women place value on delivery by traditional midwives. The social role played by traditional midwives in communities is recognized, respected and therefore, their attendance is highly valued. They provide services that the formal health care system does not, including postpartum care at home. Furthermore, some women believe that childbirth related complications are caused by witchcraft and traditional midwives are perceived as better equipped to intervene in these cases. Another instance is the control that the health facility is a harsh setting for childbirth. Another issue is the nasty and negative behaviour and attitude of most nurses and midwives towards their clients. These poor staff attitudes include rudeness, undeserved, inappropriate reprimand, shouting at women in labour, lack of empathy, refusal to assist, refusal to allow women in labour to touch or hold a midwife, threatening patient in 
labour with poor outcome if they do not comply with instructions, denying women services and lack of moral support and encouragement to exhausted women in labour. There are not such things with traditional midwives (Ihejiamazu, 2002).

Regardless of where a woman chooses to birth, she deserves to be treated with respect. She deserves to make informed choice, without coersion or threats. She deserves to choose if she wants to labour in bed or if she wants to walk or if she wants to use a birth ball. She deserves respect so that she will to not feel like she is in an assembly line. She deserves to actively put to birth her baby, rather than acting like a passive participant. Women deserve the right to choose what they want based on past experiences and the situation that they now find themselves (Neonatal Document, 2006).

For instance, a personal account showed where a woman narrated her experiences: "The nurse put my finger into my vagina and asked what I could feel. I said it was the baby's head and I asked her whether I should push" She retorted: "What are you lying there for" (Oral interview).

Another woman gives her gory account thus: "The nurse was so nasty and put fear in me and threatened that they would take me to the theatre if I dare push again. She said because of the pushing I had soiled my pad and so, she ordered that I should go and dispose of it myself. In fact, this was difficult, but I had to crawl to the disposal bin. When she came back to realized the baby was out. She asked me why I had not told her the baby was about to come. But I did not know. It is her job and she should have known that the baby was coming. She was the one who had listened to the baby and had attended to me. How could I have known, that the baby was about to come out" (Oral interview) ?

However, not all nurses and midwives show negative attitude and behaviour towards their patients. All women expressed a desire to have staff with a positive attitude. Some mothers described the positive staff attitude they have experienced. (Staff in this context means nurses and midwives). These included: giving reassurance, encouragement and politeness, provision of mosquito nets, patience and tolerance.

One woman expressed her experience: The main person who assisted me was the nurse who asked me to be patient; kept coming to see how I was faring. She was the one who treated me kindly, performed the episiotomy and sutured it. When I bled on the floor, she cleaned. She received the baby and the placenta. She cut the cord and made sure the placenta was out (Oral interview).

Another woman said "The midwives I met when I arrived were nice to me, but one of those who came to relieve others kept shouting at me and told me to keep quiet while screaming in pain. I'm glad she didn't attend to my delivery" (oral interview).

Women expect attending midwives to provide guidance and counseling. However, the accounts indicate that providers of childbirth services expect women to know what to do at various stages during labour and delivery and that their lack of knowledge attracts reprimand from some attending nurses and midwives. According to some women; interviewed for this study, "the attendant should be patient with me since it is my first delivery." "They should be patient and tolerant when I am in pain and shouting. Also when I can't push properly, they should understand."

Another woman said "the facility should acquire an ambulance to make it easy to transfer women in cases of emergency:

Women expect humane and courteous treatment during labour and consciously change their place of delivery if they experience degrading, negative and unacceptable behavior and a mother explains "I wanted to deliver in the hospital, but while attending antenatal clinic, a nurse was rude to me so I changed my mind and delivered with a traditional birth attendant" (oral interview).

Neonatal document 2006 ascertains that, if it is to have a healthy child, go to the hospital and take advantage of the modern world. Ten percent of babies need some type of resuscitation at birth. A good child birth experience. Anonymous (2006) said that, there are a lot of woes in the world that western medicine cures and there are still no guarantees that you will have a perfect baby by going to the hospital. However, the odds of having an adverse effect at home (particularly with your first child) are so much higher than in a hospital in which antibiotics and c-section are at least available with a competent health care provider present at delivery. And that's what happens when a home delivery goes bad - the baby becomes a "no brainier" because it has no access to oxygen. Anonymous further said that, I attempted to have an out of hospital (birthing centre) birth with my baby, and we ended up having emergency c-section (prolapsed cord).

The Doc also said that complications were an exception and not the rule. Delivery at home is like throwing to the wind and I believe it is one of the most selfish acts that mother can commit."I would not have been able to live with myself if my healthy baby died or was brain damaged because of home complication that could have been quickly remedied or prevented in the hospital all in the name of (good birth experience"). Dreamoni (2006) stated that having a baby at a hospital is like having insurance you have a backup plan in case you get into trouble. 
My second son died from lack of oxygen, and shoulder dystocia as a result of home birth. Hospitals have their place. I had pre-eclampsia with both of my pregnancies, severely the second time around, and I needed a hospital for my health and safety. I worked in birth centres, both freestanding and attached to a hospital. I think those are the best of both worlds. I would not personally have a home birth, but would not condemn those who do, provided that they utilize a competent health care provider, who knows when to say "we need to go to the hospital..." I regret being lumped with those who have no education but learned to birth babies from other conduct of people (Dawn, 2006).

All women deserve to know the truth and make their decision based on the truth. Pang et al (2002) make much of the fact that 10 of the 20 babies who died had diagnoses of congenital heart disease or respiratory distress. They argue that the outcome in these cases might have been different if they had the baby born in the hospital. An additional three babies in the home birth group had major congenital anomalies. This is an indictment of home birth delivery. Thirteen of the 20 babies who died suffered from unanticipated congenital anomalies. During the period of the farm study, neonatal mortality rate dropped from $14.2 / 1000$ to $6.6 / 1000$ for an average of 9.1/1000. Neonatal mortality for babies born to white women dropped from $13 / 1000$ to $5.7 / 1000$ for an average of $8.3 / 1000$. These are nonutility rates, and do not include babies who died within 28 days after birth

\section{Research Methods}

\subsection{Research Design}

The research design adopted in this study was survey. In a survey design, according to Isangedighi, Joshua, Asim and Ekuri (2004), the researcher attempts to obtain a picture of the present conditions of particular phenomena. Questionnaires and interviews are used for data collection.

This particular research design was adopted because the variables under study were examined as they existed when the study was carried out. The study also involves very large populations that were only covered through a sample using questionnaires and describing the picture of the situation instead of drawing inference. In this study, the independent variables, trained midwives and traditional midwives, was a measure of differences; while dependent variables already exist in the control of delivery pain of women.

\subsection{Research Area}

The area covered by this study is Cross River State of Nigeria. Cross River State is located in the South Eastern flank of the Federal Republic of Nigeria in what is known as the south-south zone, between latitude $5^{0} 32$ and $4^{0} 27$ north of the equator, and longitude $7^{0} 50$ and $9^{0} 28$ east of the Greenwich meridian. Cross River State as it exists today consists of eighteen (18) local government areas namely Abi, Akamkpa, Akpabuyo, Bakassi, Bekwarra, Biase, Boki, Calabar Municipality, Calabar South, Etung, Ikom, ObanlikumObudu, Obubra, Odukpani, Ogoja, Yakurr, and Yala.

According to the state ministry of lands and surveys, the state occupies a land mass of 23,074, 425 square kilometers. The population has been estimated at about 2.6 million people by the states planning commission and national population commission respectively. The state is bounded in the north by Benue state, in the south by the Atlantic ocean, in the west by Akwalbom state and Abia state to the North West by Ebonyi state and to the east by the Republic of Cameroon. For proper supervision of health centres, the health centres and hospitals in the state are divided into three Senatorial Districts.

1. Southern Senatorial District

2. Central Senatorial District

3. Northern Senatorial District

\subsection{Population of the Study}

The population of this study is made up of all post-natal women in Cross River State, who have their names registered as mothers into the state polio immunization registers in 2009. The comprehensive registers available at all local government health centers with the state show that there were a total of $(78,814)$ Seventy-eight thousand, eight hundred and fourteen postal-natal women in the state during the period. A break-down of the population figure is shown in the Table 1.

\subsection{Sampling Procedure}

Two sampling techniques were adopted in selecting the sample for the study. These are the simple random and accidental sampling techniques. The former was used in selecting equal number of Local Government Areas (LGAs) for the study from each of the three Senatorial Districts. Four Local Government Areas were selected from the Southern Senatorial District, three from the central and two from the northern senatorial districts. From each Local Government Area 40 respondents were used for the study.To carry out the selection of health centres all the names of the centres in each Local Government Areas were written down on a piece of paper and then subjected to selection through simple 
random sampling technique of the fact that all health centres have polio immunization registers with the addresses of contact families in them. The post-natal women were reached through the polio immunization registers of the selected health centres.

Table 1. Study population by senatorial district and local government area

\begin{tabular}{llr}
\hline Senatorial District & Local Government Area & $\begin{array}{r}\text { No. Of } \\
\text { Women }\end{array}$ \\
\hline Southern & Bakassi & 312 \\
& Akpabuyo & 3,358 \\
& CalabarMunicipality & 5,051 \\
& Calabarsouth & 4,972 \\
& Odukpani & 4,215 \\
& Akamkpa & 3,119 \\
& Biase & 6,012 \\
Central & Total & 27,039 \\
& Yakurr & 6,218 \\
& Abi & 4,964 \\
& Obubra & 5,097 \\
& Ikom & 5,136 \\
& Etung & 2,425 \\
& Boki & 5,611 \\
Northern & Total & 29,451 \\
& Obanliku & 4,222 \\
& Obudu & 3,961 \\
& Bekwara & 5,725 \\
& Ogoja & 3,853 \\
& Yala & 4,563 \\
& Total & 22,324 \\
& Grand total & 78,814 \\
\hline
\end{tabular}

Source: Polio Immunization Register

The accidental sampling technique was used in selecting the women for the study. This technique is normally used for convenience when other techniques seem difficult to apply. A total of 415 post-natal women were reached and administered questionnaires. From this number 360 questionnaire of women who have delivered in only one of government hospital/health centre or traditional delivery home were finally selected as sample. For this study the researcher visited as many families found in the register as possible until the required number of questionnaires (for both women who delivered in government hospitals/health centres and in the traditional centres) were completed.

\subsection{Sample Size}

The sample for this study was made up of 360 post natal women selected from nine (9) Local Government Areas across the three Senatorial Districts of Cross River State, Nigeria. Out of the 360 women selected, 160 were from the Southern Senatorial District, 120 from the Central Senatorial District and 80 from the Northern Senatorial District.

\subsection{Instrumentation}

The instrument for the study is a 36 item questionnaire called Delivery Pain Control Questionnaire (DPCQ). The questionnaire is divided into two sections (A and B). Section A is on personal data and is made up of 7 items. Section B is on control of delivery pain and it is sub-divided into two sub-sections with six items each. The sub-sections are on control of pain from care giving, pain from attitude of midwives,

\subsection{Validation of Instrument}

In order to validate the instrument, delivery pain control inventory questionnaire (DPCIQ)

Copies were presented to the researcher's supervisor and experts in measurement to scrutinize for face validity. Face validity of an instrument is obtained through a superficial examination of content of the research instrument and the establishment of the fact that the content can measure what it wants to measure (Kerlinger, 1987)

\subsection{Reliability of Instrument}

In order to determine the reliability of the instrument, a trail test was conducted with a group of 50 post-natal women in AkwaIbom State. The 50 post-natal women who took part in the study were captured twice during polio immunization week. The researcher employed five health staff who did not take part in the immunization and attached each of them to a team to collect data from mothers as the children were being immunized. This was done twice during two consecutive immunizations.

During the second data collection exercise the employed assistant for the trial test were made to repeat the 
immunization areas they covered in the first test to ensure that the women who completed the questionnaire in the first visit were spotted and made to complete the same type of questionnaire the second time. The two questionnaire responses for the 50 respondents were then used for a test-retest reliability estimate. The results of the estimate are presented in Table 2.

\subsection{Procedure for Data Collection}

The questionnaire was administered by the researchers, assisted by some health staff that was employed by the researchers.

Table 2. Test-retest reliability estimates of variables on control of delivery pain among post-natal women $(\mathrm{N}=50)$

\begin{tabular}{|c|c|c|c|c|c|}
\hline Independent Variables & $\begin{array}{l}\text { No. of } \\
\text { items }\end{array}$ & Administration & $\mathrm{X}-$ & $\mathrm{SD}$ & $\mathrm{Rxx}$ \\
\hline $\begin{array}{l}\text { Control of women towards } \\
\text { delivery pain caused by amount of } \\
\text { care giving. }\end{array}$ & 6 & $\begin{array}{l}1^{\text {st }} \\
2^{\text {nd }}\end{array}$ & $\begin{array}{l}13.42 \\
12.68\end{array}$ & $\begin{array}{l}2.63 \\
2.81\end{array}$ & 0.67 \\
\hline $\begin{array}{l}\text { Control of women towards } \\
\text { delivery pain caused by attitude } \\
\text { of midwives }\end{array}$ & 6 & $\begin{array}{l}1^{\text {st }} \\
2^{\text {nd }}\end{array}$ & $\begin{array}{l}12.93 \\
12.86\end{array}$ & $\begin{array}{l}2.48 \\
2.65\end{array}$ & 0.77 \\
\hline
\end{tabular}

Source: Fieldwork, 2010

The respondents were visited at their individual homes using the addresses of the polio immunization registers kept at the various health centers. Literate women were allowed to tick the questionnaires after a thorough explanation of the instructions, while illiterate women were assisted by the researcher or their assistants as the case may be by reading out the items in the language understood by the respondents (using an interpreter). The researcher and her assistant waited at each home and retrieved copies of the questionnaire the very moment they were completed.

\subsection{Scoring of the Instrument}

The two sections of the questionnaire were coded separately and scored following a four (4) point Likert scale format ranging from very strongly agrees (VSA) to very strongly disagree (VSD). The following scores were attached to responses on the side.

$\begin{array}{lc}\text { Response } & \text { Score } \\ \text { Very strongly agree (VSA) } & 4 \text { points } \\ \text { Agree (A) } & 3 \text { points } \\ \text { Disagree (D) } & 2 \text { points } \\ \text { Very strongly disagree (VSD) } & 1 \text { point }\end{array}$

Scoring was reversed for items that were negatively worded with a score of 4 reversed to 1 for a very strongly disagree response and vice versa. The coding schedule for the major variables is presented in Table 3.

\section{Results and Discussion of Findings}

\subsection{General Description of Data/Variables}

The study was on the western and traditional educational background of midwives and delivery pain control in Cross River State, Nigeria. The independent variable of the study is place of delivery categorized in this study into two, namely; delivery through trained midwives and delivery through traditional midwives. Data for this variable was nominal and was collected through a personal data item in section A of the questionnaire. This item requested respondents to tick $(\sqrt{ })$ who they have experienced child delivery under whether it was under a trained midwife, traditional midwife or under both. No respondent said she had been delivered by both. Of the 360 respondents, $221(61.4 \%)$ said they were delivered by trained midwives while $139(38.4 \%)$ said they were delivered by traditional midwives.

The major dependent variable in the study is control of delivery pain. This dependent variable was considered undertwo sub-variables, namely; delivery pain arising from nature/degree of care giving, pain from attitude of midwives. Data for these variables were collected using a four-point Likert type scale. The data were accordingly coded and analyzed. The summaries of descriptive analyses are presented in Table 3.

\subsection{Hypothesis-by-Hypothesis Presentation of Results}

Independent t-test statistical technique was used in analyzing data for this hypothesis. The results of the analyses are presented in Table 3. 
Table 3. Descriptive analysis of all continuously measured variables in the study

\begin{tabular}{|c|c|c|c|c|}
\hline $\mathrm{S} / \mathrm{NO}$ & Variables-control of: & $\mathrm{N}$ & $\mathrm{X}$ & $\mathrm{SD}$ \\
\hline 1 & Pain caused by nature of care giving & 360 & 18.03 & 4.60 \\
\hline 2 & Pain caused by attitude of midwives & 360 & 17.04 & 4.92 \\
\hline 3 & Total control of pain & 360 & 90.63 & 15.78 \\
\hline
\end{tabular}

Source: Fieldwork, 2010

\subsection{Hypothesis Two}

Trained under western education do not differ significantly from traditional midwives in their control delivery pain caused by attitude towards post natal women. Independent t-test statistical technique was employed in testing the hypothesis. The results of the analyses are presented in Table 4.

Results of analysis in Table 6 show that the calculated t-value of 2.340 is greater than the critical t-value of 1.96 at .05 level of significance with 358 degrees of freedom. This means that, trained midwives differ significantly from traditional midwives in their delivery pain caused by attitude towards post-natal women.

Table 4. Independent t-test analysis of the influence of western education of midwives on delivery pain control through attitude towards post natal women

\begin{tabular}{|c|c|c|c|c|}
\hline Variables & $\mathrm{N}$ & $\mathrm{X}$ & SD & $\mathrm{t}$ \\
\hline $\begin{array}{l}\text { Delivery pain control by trained under western education through attitude } \\
\text { towards post natal women. } \\
\text { Delivery pain control by traditional midwives through attitude towards post } \\
\text { natal women }\end{array}$ & 221 & 16.56 & 5.245 & $2.340 *$ \\
\hline
\end{tabular}

* significant at $.05 ; \mathrm{df}=358$; critical $\mathrm{t}=1.96$

Source: Fieldwork, 2010

This implies that traditional midwives are more positive in delivery pain control through attitude towards pot natal women than their counterparts who are trained midwives.

Hypothesis three. This hypothesis was tested using independent t-test statistical technique. The results of the analysis are presented in Table 5.

Results of analysis in Table 5 show that the calculated t-value of 14.528 is greater than the critical t-value of 1.96 at 0.05 level of significance with 358 degrees of freedom. This means that, trained midwives differ significantly from traditional midwives in their control of delivery pain through clients' care giving. The result shows that, trained midwives are more positive in delivery pain control through clients' care giving than their counterparts who deliver under traditional midwives.

Table 5. Independent t-test analysis of the influence of western education of midwives on delivery pain control through clients' care giving

\begin{tabular}{|c|c|c|c|c|}
\hline Mode of delivery & $\mathrm{N}$ & 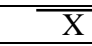 & SD & $\mathrm{t}$ \\
\hline $\begin{array}{l}\text { Delivery pain control by trained under western education through clients care } \\
\text { giving. }\end{array}$ & 221 & 19.89 & 3.66 & $14.528 *$ \\
\hline Delivery pain control by traditional midwives through clients' care giving. & 139 & 15.07 & 4.408 & \\
\hline
\end{tabular}

* significant at $.05 ; \mathrm{df}=358$; critical $\mathrm{t}=1.96$

Source: Fieldwork, 2010

\subsection{Summary of Findings}

(1) Trained under western education are significantly better than traditional midwives in their control of delivery pain through clients' care giving. They could be summarized into two main issues. These are:

2) Traditional midwives are significantly better than trained under western education system in their control of delivery pain caused by attitude towards post-natal women.

\subsection{Summary of the Study}

Two hypotheses were tested for the study. Data were obtained by means of questionnaires specially developed for the study. Independent t-test analyses were used for data analysis. The findings revealed that 
1) Trained under western education differ significantly from traditional midwives in their control of delivery pain caused by amount of care giving. The results show that women who deliver under western education have a more positive control of delivery pain caused by amount of care giving than women who deliver under traditional midwives.

2) Trained midwives under western education differ significantly from traditional midwives in their control of delivery pain caused by attitude of midwives.

\section{References}

Bannerman, R. (1982). A book for midwives. London: Macmillan.

Bannerman, R. H. (1982). Traditional medicine in modern health care. World Health Forum, 3, 8-26.

Bevis, R. (1984). Anaesthesia in midwifery. London: Baillnere Tindall.

Colleen. (2006). Neonatal document. Monday April 17, 2006. http://dx.doi.org/10.1002/14651858.CD000007

Cooper, M. A. (2003). Textbook for midwives ( $4^{\text {th }}$ ed.). London: Oxford University Press.

Crafter, H. (1997).Health Promotion in Midwifery: Principles and Practice. London: Arnold.

Deakin, B. A. (2001). Alternative positions in labour and childbirth. British Journal of Midwifery, 9 (10), $620-625$. http://dx.doi.org/10.12968/bjom.2001.9.10.12694

Department of Health (DOH) (1992). The health of the nation. London: Her Majesty's Stationary Office.

Department of Health (DOH) (1998).Our healthier nation: A contact for health. London: Her Majesty's Stationary Office.

Dreamoni, (2006). Neonatal document. Monday April 17, 2006. http://dx.doi.org/10.1002/14651858.CD000007

Department of Health (DOH) (1999).Making a difference. Strength: The nursing and midwifery and health visiting contribution to health and health care. London: Department of Health.

Fairlie, F. M., Morgan, L., Walker. J. J., \& Elbourne, D. (1999). Intranuscular opioids for maternal pain relief in labour a randomized controlled trial comparing pethidine with diamorphie. British Journal of Obstetrics and Gynecology, 106, 1181-1187. http://dx.doi.org/10.1111/j.1471-0528.1999.tb08145.x

Halldorsdother, S., \& Karidottir, S. I. (1996). Journeying through labour and delivery controls of women who have given birth. Midwifery Journal, 12, 48-61. http://dx.doi.org/10.1016/S0266-6138(96)90002-9

Ihejiamaizu, E. C. (2002). Issues in population policy and health care administration.Calabar: African Scholars Publishers.

Isangedighi, A., Joshua, M., Asim A., \& Ekuri E. (2004). Fundamentals of research and statistics in education and social science.Calabar: University of Calabar Press.

Jrsph, (2007). Journal of the Royal Society for the Promotion of Health, 121(2), 119-124.

Kabegama, K., \& Miyoshi, M. (2001). Longitudinal study of the intensity of memorized labour pain. International Journal of Nursing Practice, 7, 46-53. http://dx.doi.org/10.1046/j.1440-172x.2001.00286.x

Kerlinger, F. N. (1987). Foundations of Behavioural Research. New York: Holt Phinehart and Winston.

Kitzinger, S. (1987). Some women's experiences of epidurals: A descriptive study. London: National Childbirth Trust.

Kitzinger, S. (2000). Some cultural perspective of birth. British Journal of Midwifery, 8 (12), 746-750. http://dx.doi.org/10.12968/bjom.2000.8.12.8037

Lucas, A. O., \& Gilles, H. M. (2003). Short textbook of public health medicine for the tropic (9 ${ }^{\text {th }}$ ed.). London: Arnold.

Mander, R. (1992). The control of pain in labour. Journal of Clinical Nursing, 1(1), $219-223$. http://dx.doi.org/10.1111/j.1365-2702.1992.tb00102.x

Mander, R. (2000). The meaning of labour pain or the layer of onion? A women oriented view. Journal of Clinical Nursing, 18, 133-141.

Maternal and Neonatal Health (MNH) (2000). Safe motherhood: An orphan initiative. Nairobi: University of Nairobi and Population Council.

Maternal and Neonatal Health (MNH) (2007).The traditional birth attendant: linking communities and service.www.mnh.jhpiego.org

Niven, C., \& Brodie, E. (1995). Memory for labour pain: Content and quality. Pain, 64, 387-392. http://dx.doi.org/10.1016/0304-3959(95)00134-4 
Nursing and Midwifery Council (2002). Code of professional conduct. London: Nursing and Midwifery Council.

Odent, M. (1984). Birth re-born. London: Souvenir Press.

Pang, J. W., Heffelfinger, J. D., Huang, G. J., Benedetti, T. J., \& Weiss, N. S. (2002). Outcome of planned birth in Washington state: $1989-1996 . \quad$ Obstetric $\quad$ Gynecology, $100 \quad$ (2), http://dx.doi.org/10.1016/S0029-7844(02)02074-4

Rajan, I. (1993). Control of pain and pain relief in labour, the gult between the experience and observation. Midwifery, 9, 136-143. http://dx.doi.org/10.1016/0266-6138(93)90020-S

Walsh, (2000). Evidence-based care series birth environment. British Journal of Midwifery, 8 (5), $276-278$. http://dx.doi.org/10.12968/bjom.2000.8.5.8131

World Health Organization (WHO) (1990). Local government focused acceleration of primary health care: the Nigerian experience. Geneva: World Health Organization.

World Health Organization (WHO) (1992). Local government focused acceleration of primary health care: the Nigerian experience. Geneva: World Health Organization.

Yusuf, K. B. (1990). Relationship between health care system in times of illness and socio-economic status in Ago-Iwye, Ogun State. Journal of Nursing, 1(2), 121-125.

\section{$(\mathrm{cc}) \mathrm{BY}$}

This work is licensed under a Creative Commons Attribution 3.0 License. 